\title{
A Rare Case of Severe Hemophilia B Combined with Hematomesenchymal Dysplasia
}

\author{
Fatima Muratova $^{1 *}$, Zhanna Mussabekova ${ }^{1}$, Maxut Kazymov ${ }^{1}$, Viktor Sturov ${ }^{2}$ \\ ${ }^{1}$ Department of Family Medicine, Semey Medical University, NCJSC, Semey, Republic of Kazakhstan; ${ }^{2}$ Novosibirsk State \\ University, Institute of Medicine and Psychology V. Zelman, Novosibirsk, Russia
}

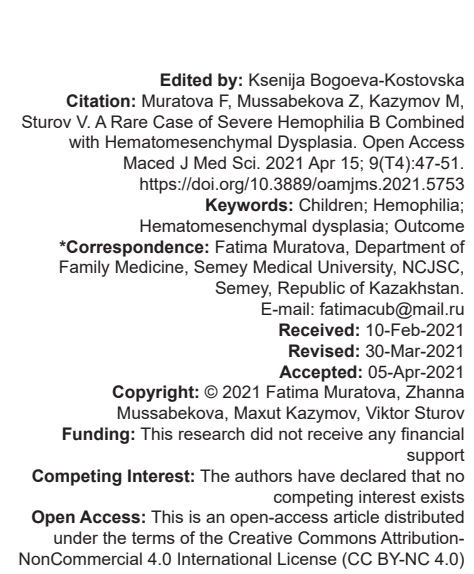

\section{Abstract}

BACKGROUND: The prevalence of hemophilia $B$ in the global population is approximately 1:60,000. Undifferentiated systemic mesenchymal dysplasia (uSMD) is diagnosed rather frequently, about 1:5, according to Russian authors no data on USMD prevalence in other countries are available. The combination of hemophilia and USMD has grouped under the term hematomesenchymal dysplasia (HMD). This combination significantly worsens the clinical picture, prognosis, and quality of life of the patient.

AIM: In this article, we present a rare clinical case of a child with a combination of hemophilia B and HMD.

CASE REPORT: A clinical case of a male patient, 5 years old with hemophilia B, severe form combined with HMD complicated by hemothorax, abscessed pulmonary lobe hematoma has presented. The presence of HMD and the above complications had an unfavorable effect on the severity of the clinical picture and the abnormal response to treatment. The main diagnostic procedures were the assessment of the phenotypic signs of HMD in combination with laboratory and instrumental examination methods such as ultrasound, computed tomography (CT) scan, and echocardiography. Vital treatment is factor IX replacement therapy and supportive one.

CONCLUSION: This clinical example highlights the importance of clinical alertness to hereditary coagulopathies which often lead to life threatening, sometimes disabling complications that significantly reduce the quality of life of children with hemophilia. Consequently, full-scale epidemiological studies of the prevalence of HMD in the population are an urgent task for the near future.

\section{Introduction}

The hematomesenchymal dysplasia (HMD) is a variant of undifferentiated systemic mesenchymal dysplasia (uSMD) of connective tissue in which the main manifestations are symptoms due to disorders of the hemostasis system. The main pathogenetic link in uSMD is a genetic quantitative and/or qualitative defect in the synthesis of proteins that form the extracellular matrix (collagen and fibrillin). It has been found that the signs of uSMD are more common in patients with extremely severe and severe forms of hemophilia [1]. Taking into account that hemostatic disorders can be manifested by thrombophilia, dysfibrinogenemia, coagulopathy with decreased levels of various clotting factors, thrombocytopathy with both hypoaggregation and hyperaggregation of platelets and clinically expressed not only by increased bleeding but also by thrombosis, a detailed examination and identification of these patients is necessary to avoid complications at different periods of surgical intervention [2]. Hemophilia B is an inherited X-linked bleeding disorders caused by mutations of the F9 gene in which the blood does not clot properly due to a low level of factor IX. This can lead to spontaneous bleeding as well as bleeding following injuries or surgery [3], [4]. Globally, the incidence of hemophilia is little known, estimated at over 400,000, according to the World Federation of Hemophilia. The worldwide prevalence of hemophilia $B$ is $1: 60,000$. The number of people with hemophilia in the United States is between 30,000 and 33,000 the exact number is unknown. In the Republic of Belarus, the prevalence of hemophilia is $0.06 \%$ and is average among European countries [5], [6]. The ratio of type $A$ hemophilia cases to type $B$ hemophilia cases was 3.8:1, which is typical [7], [8].

In this paper, we describe the clinical case of a 5-year-old male patient with severe hemophilia $B$, which presents as an inhibitor form with life-threatening complications such as hemothorax and abscessed hematoma. This course of the clinical picture in the patient is associated with the presence of background pathology, in particular HMD.

\section{Case Report}

A 5-year-old boy admitted as an emergency case with complaints of bleeding from the mouth, 
vomiting blood, and breathing difficulties. According to the mother, the child had bitten his tongue. Two weeks before admission, the child had hospitalized with the diagnosis: Hemophilia $B$, severe course, complicated by hemothorax on the right side, respiratory failure II, and post-hemorrhagic severe anemia. In the clinic, while inserting the subclavian catheter on the right side, the patient had a hemothorax. Therefore, the Bülau drain placed. The child received factor VIII, cryoprecipitate, and fresh frozen plasma (FFP) for replacement purpose [9]. The patient was diagnosed with hemophilia at the age of 10 months. An allergy was to ampicillin, penicillin (rash), glucose (edema, chills), thymentine (rash), and FFP (Quincke's edema). Heredity is aggravated, with a maternal sibling suffering from hemophilia B.

Transfusion history: In the hospital, at the place of residence, there were repeated vital signs blood transfusions: FFP AB (IV) fourth Rh (+) positive No. 8, erythrocyte suspension AB (IV) fourth Rh (+) positive No. 4, albumin 10\% No. 7, and cryoprecipitate No. 2.

On admission: Condition is severe due to underlying pathology, respiratory failure II, anemic syndrome, hemostatic disorders, and intoxication syndrome. The patient was feeling unwell, lethargic. Appetite has reduced. The child had recurrent episodes of low-grade fever over time. Child is underweight with no subcutaneous fat. In the musculoskeletal system, there is hypermobility of the wrist and ankle joints combined with muscle hypotonia. The skin is pale and earthy, dry to the touch. At rest, dyspnea is of a mixed nature, with the participation of the accessory muscles. The respiratory rate is $38 / \mathrm{min}$. Auscultation of the lungs on the right side has significantly decreased, and moist rales have heard on inhalation. Auscultation of the heart. The heart sounds have muffled, tachycardia of a compensatory nature with a rate of $126 / \mathrm{min}$. Capillary refill time is $2 \mathrm{~s}$. Blood pressure is $85 / 55 \mathrm{mmHg}$. There is a drain in the right pleural cavity, with a small hemorrhagic effusion.

The examinations carried out

As shown in Table 1, the patient has a decreased level of Factor IX, anemia, and inflammatory changes in his blood tests. The presence of acetone, proteinuria, and increased levels of urobilinoids in the urine also indicates inflammatory reactions in the body. The detection of bacteriological strains in physiological fluids was a consequence of hemothorax.

Ultrasound of the pleural cavity on admission: Echo picture of a slight fluid content in the pleural cavity on the right, layer thickness $12.5 \mathrm{~cm}^{3}$. After 10-day period, the volume of fluid in the pleural cavity was $8.4 \mathrm{~cm}^{3}$.

The echo pattern of a mass in the subcutaneous fatty tissue on the right side at 2-week intervals remained unchanged. At 2-week intervals within a month, there was no change in the echo pattern of minimal anechogenic fluid content in the pleural cavity on the right with a layer thickness of $9 \mathrm{~mm}$. One week before discharge, pleural ultrasound scan: Echo pattern of heterogeneous fluid content in the pleural cavity on the right side, abscessing not excluded.

Chest X-ray on day 12 of admission: Total darkening of the hemothorax on the right side. Dome of the diaphragm, mediastinum, and rib-diaphragmatic sinus are undetectable. The left side is without focal and infiltrative shadows. There is a chest tube in the $3 \mathrm{rd}$ intercostal space. Day 17 hospitalization: Hemothorax on the right side with no positive dynamics.

Computed tomography (CT) of the chest: CT scan shows signs of hemothorax on the right side; 1 week before discharge: CT scan shows signs of volumetric masses of the right lung (hematoma) with air content, chronic pleurisy on the right side. There was a positive trend.

Echocardiography:Minorcardiacabnormalities: Mitral valve prolapse I, tricuspid valve prolapse I, patent foramen ovale $(3.3 \mathrm{~mm})$, two complementary left ventricular chords. There is minor pericardial effusion. On the $70^{\text {th }}$ day of hospitalization, the echo CG findings were the same. Clinical diagnosis: Hemophilia B, severe form. Complications: Hemothorax on the right side. Hematogenous abscess of superior lobe of the right lung. Associated diagnosis: HMD. Minor cardiac

Table 1: Indicators of laboratory examination

\begin{tabular}{|c|c|c|c|c|}
\hline No. & Examination & Admission & Discharge & Reference range \\
\hline \multirow[t]{8}{*}{1.} & Complete blood count: & $84.7 \mathrm{~g} / \mathrm{l}$ & $112 \mathrm{~g} / \mathrm{l}$ & $110-140 \mathrm{~g} / \mathrm{l}$ \\
\hline & Hemoglobin & $13.7 \times 10^{9} / 1$ & $9.54 \times 10^{9} / 1$ & $5.0-14.5 \times 10^{9} / 1$ \\
\hline & White blood cells platelets & $656 \times 10^{9} / 1$ & $403 \times 10^{9} / 1$ & $202-403 \times 10^{9} / /$ \\
\hline & Neutrophils & $78.4 \%$ & $44.6 \%$ & $33.0-61.0 \%$ \\
\hline & Lymphocyte & $12.9 \%$ & 46.3 & $33.0-55.0 \%$ \\
\hline & Monocytes & $8.15 \%$ & $4.3 \%$ & $3-9 \%$ \\
\hline & Eosinophils & $0.1 \%$ & $4.37 \%$ & $1.0-6.0 \%$ \\
\hline & Basophils & $0.3 \%$ & - & $<1.0 \%$ \\
\hline \multirow[t]{8}{*}{2.} & Factor VIII & $200 \%$ & - & $50-150 \%$ \\
\hline & Factor IX & $\begin{array}{l}13 \% \text { (after emergency life-saving replacement } \\
\text { therapy with FVIII, cryoprecipitate, FFP) }\end{array}$ & $\begin{array}{l}43.4 \% \text { ( } 6^{\text {th }} \text { day of hospital admission) } \\
23-26 \% \text { (overtime), the target of factor IX level is } 20-40 \%\end{array}$ & $65-150 \%$ \\
\hline & Willebrand factor & $88 \%$ & - & $66.1-176.3 \%$ \\
\hline & Prothrombin time & 13.8 & 11.9 & $12.1-14.5 \mathrm{~s}$ \\
\hline & INR & 1.33 & 1.16 & $0.92-1.14$ \\
\hline & Fibrinogen & $5.7 \mathrm{~g} / \mathrm{l}$ & $4.95 \mathrm{~g} / \mathrm{l}$ & $2.00-4.00 \mathrm{~g} / \mathrm{l}$ \\
\hline & Thrombin time & $16.1 \mathrm{~s}$ & - & $10-15 \mathrm{~s}$ \\
\hline & APTT & $38.6 \mathrm{~s}$ & $35.7 \mathrm{~s}$ & $25.4-36.9 \mathrm{~s}$ \\
\hline 3. & Serum iron & $5.7 \mathrm{~g} / \mathrm{dL}$ & $8.2 \mathrm{~g} / \mathrm{dL}$ & $11.9-15.0 \mathrm{~g} / \mathrm{dL}$ \\
\hline 4. & Urine test & Acetone, proteinuria, urobilinoids $8 \mathrm{mg} / \mathrm{dL}$ & Not detected & Not detected \\
\hline 5. & Bacteria culture test & Pleural fluid: Klebsiella pneumoniae & Sputum: Streptococcus pneumoniae Klebsiella oxytoca & Not detected \\
\hline
\end{tabular}




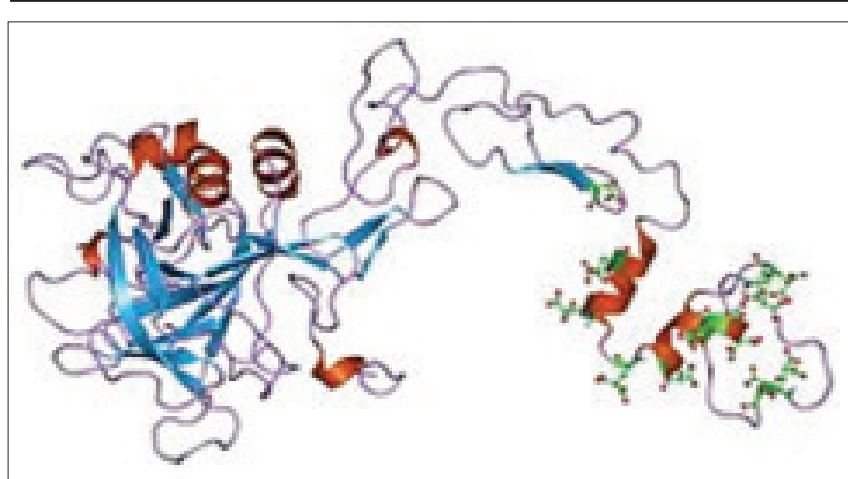

Figure 1: Visual representation of factor IX (Christmas factor) protein $\alpha$-globulin, pro-enzyme (protease)

anomalies: Mitral valve prolapse Grade I, tricuspid valve prolapse Grade I, patent foramen ovale (3.3 $\mathrm{mm})$, two complementary left ventricular chords. Small pericardial effusion. Iron deficiency anemia I degree, of mixed genesis (post-hemorrhagic, alimentary).

From the moment of admission, for 2 weeks on vital signs IX factor replacement therapy, Immunin at $600 \mathrm{IU} \times 2$ times a day by intravenous stream slowly was administered. From the $32^{\text {nd }}$ to the $84^{\text {th }}$ day of hospitalization on life indications, the substitution therapy with IX factor (Octanine) was conducted under the scheme of $66 \mathrm{IU} / \mathrm{kg}$ per day: $1000 \mathrm{IU} \times 1$ time/day by intravenous stream slowly. The patient tolerated the treatment satisfactorily. In parallel with the primary therapy, the child received antibacterial therapy, antifungal therapy, for passive immunostimulation: Octagam $3 \mathrm{~g}$ intravenous drip once a day for $5 \mathrm{~h}$, hemostatic, antiviral treatment, iron, and bronchodilators. Transfusions of blood products have administered on vital signs. In the course of observation, a clinical effect has noted in the background of the ongoing substitution therapy: The hemorrhagic syndrome has subsided; a positive response of the initiation of Octanine: The level of IX factor on the $6^{\text {th }}$ day of hospitalization has increased to $43.4 \%$. During follow-up after repeated injections, it remained between $23 \%$ and $26 \%$ without the hemorrhagic syndrome. The drainage catheter removed on the $28^{\text {th }}$ day of hospitalization. Subsequently, hypergranulation developed at the site of the catheter. On day 47 of admission, surgery performed: Excision of granulation tissue. On day 55 after admission, thoracentesis and drainage of the right pleural cavity performed. Thoracoscopy revealed pleural adhesions. There is a medical council recommended bronchoscopy. On the $70^{\text {th }}$ day of admission, bronchoscopy under anesthesia performed after that narrowing of the upper and middle lobe bronchi on the right side with anemic bronchial mucosa was detected.

The child's condition has improved as a result of the treatment, and the child is moderately ill and stable. He does not feel unwell. There is no hemorrhagic syndrome. Bleeding has not recurred. The child's body temperature is normal. Skin and visible mucous membranes are pink and clean. Hemodynamics is stable. The lungs breathe through all the fields on the left side. The breathing has shortened through all the fields on the right side, without rales. The medical council decided that the diagnosis "Abscessed hematoma" remains and recommended to refrain from surgical treatment until the hematological parameters stabilize, positive clinical dynamics: Temperature normalization for more than 10 days, readmission in 3 months for monitoring to continue treatment and decide on next tactics of treatment. There should be monitoring of IX factor and IX factor inhibitor levels once a week. With replacement purpose, continuous lifelong intravenous very slowly IX factor (Octanine, etc.) on a regimen: 500 IU once a day intravenously very slowly 3 times a week. The total hospital admission period was 84 days.

\section{Discussion}

Factor IX is a component of plasma thromboplastin (Figure 1). The pathogenetic mechanisms of bleeding in hemophilia are based on disruption of the primary phase of blood clotting - thromboplastin formation - due to a hereditary deficiency of the antihemophilic factor [10].

The hemophilia has characterized by a hematomas type of bleeding, which is confirmed by this clinical case. The spectrum of symptomatic manifestations can vary; there may be hemarthroses, hematomas of various localization, late hemorrhages of long duration unresectable, and often life threatening [9], [11], [12], [13]. HMDs refer to a group of hereditary hemorrhagic diatheses that are based on both developmental and structural disorders of connective tissue and associated abnormalities of the hemostasis system. It has been established that hemorrhagic and thrombotic manifestations of uSMD serve as a high risk of intra- and post-operative complications and require adequate pre-operative verification and pathogenetic correction [2]. In the presence of an underlying pathology as GMD in hemophilia B, supplementary correction with hemostatic drugs is necessary also with the main replacement treatment by IX factor under constant laboratory monitoring.

A patient developed an extensive hemothorax of almost the entire right lung after iatrogenic factor, followed by the abscessed upper lobe of the right lung. Despite adequate treatment, in the course of the disease, the symptom complex did not follow the classical case due to the presence of a background pathology, HMD, namely, a congenital developmental defect of the connective tissue endothelium. There is no doubt about the relevance of HMD. Analysis of the current situation shows that this background pathology has not been adequately addressed in practical 
healthcare, hence, there is a lack of awareness among doctors and a lack of uniform terminological approaches and precise clinical algorithms for the management of patients. According to the literature, there are age-related criteria for the manifestation of HMD in children. For example, at the age of 4-5 years, the first clinical precursors, such as small cardiac abnormalities, appear, as confirmed by our clinical case: Mitral valve prolapse Grade I, tricuspid valve prolapse Grade I, patent foramen ovale (3.3 $\mathrm{mm}$ ), two extra left ventricular chordae, and minimal pericardial effusion. The presence of the abovementioned small cardiac anomalies is a confirmation of valve syndrome. As for the musculoskeletal system, the patient has the asthenic type of constitution, joint hypermobility syndrome combined with hypotrophy and muscle hypotonia. In addition, the child tended to allergic reactions, delayed healing of postoperative wounds with the development of skin hypergranulation [14], [15], [16]. The diagnosis of HMD has based on the detection of coagulation-plasma hemostasis (dysfibrinogenemia, reduced Christmas factor, and prolonged thrombin time) and five clinical and instrumental signs of USMD, multiorgan, and multisystem lesions (hemostasis, bronchopulmonary, cardiovascular, connective tissue, and immune system) [2], [17]. The diagnosis of USMD verified according to the 2016 national recommendations of the Russian scientific medical society of therapists on the diagnosis, treatment, and rehabilitation of patients with connective tissue dysplasias, according to the criteria of MilkovskaDimitrova and Karkashev (1985); joint hypermobility was determined according to the tests of Beighton (1973) with an assessment of severity according to the 9-point system, Velaskakis criteria scale (1984) [15], [18]. This case contributes as proof to the scientific evidence-based and clinical experience. The study of this problem requires extensive research and is the prerogative of the near future.

\section{Conclusion}

The presence of coexisting pathologies, such as HMD, not only worsens the clinical course of hemorrhagic syndrome in hemophilia B but is also an obvious risk factor, contributing to more possible complications, manifesting as polyorganic and polysystemic lesions, resulting in an earlier onset of an unfavorable prognosis. This clinical example highlights the importance of clinical alertness to hereditary coagulopathies, which often lead to life threatening, sometimes disabling complications that significantly reduce the quality of life of children with hemophilia $\mathrm{B}$.

\section{Author's Contributions}

FM analyzed the clinical case, wrote the manuscript. All authors have reviewed and edited the draft and agree with the contents of the paper.

\section{References}

1. Babtseva AF, Shanova OV, Boychenko TE, Arutyunyan KA, Romantsova EB. Connective Tissue Dysplasia in Children and Adolescents. Blagoveshchensk: Educational Guidance for Interns and Residents Studying Pediatrics, Amur State Medical Academy; 2010. p. 85

2. Firsova LV, Sturov VG, Kovynev IB. Disorders of blood coagulation final stage in children with hematomezenchimal dysplasia syndrome under conditions of background surgical pathology. Bull SO RAMN. 2014;34(6):54-60

3. Centers for Disease Control and Prevention. National Center on Birth Defects and Developmental Disabilities. Atlanta, GA: Centers for Disease Control and Prevention; 2021. https://doi. org/10.1037/e303462004-001

4. Butterfield JS, Hege KM, Herzog RW, Kaczmarek R. A molecular revolution in the treatment of hemophilia. Mol Ther. 2020;28(4):997-15. https://doi.org/10.1016/j.ymthe.2019.11.006 PMid:31843450

5. National Hemophilia Foundation. Available from: http://www. hemophilia.org/About-Us/Fast-Facts. [Last accessed on 2020 Dec 15].

6. Dashkevich EV, Olkhovik YV, Rud MS, Volobuyeva VV, Mikhailovskaya EN. Analysis of the prevalence of hemophilia in the republic of Belarus. Med News. 2014;8:29-30.

7. Chernov VM. Clinical Significance of Medical and Economic Monitoring of Hemoblastosis and Hereditary Coagulopathies in Children. Moscow: Dissertation of Doctor of Medicine Russian State Medical University Moscow; 2003. p. 291. Available from: http://www.dslib.net/infekcion-bolezni/klinicheskoe-znacheniemediko-jekonomicheskogo-monitoringa-gemoblastozov-i.html. [Last accessed on 2021 Apr 27].

8. Marlar RA, Strandberg K, Shima M, Adcock DM. Clinical utility and impact of the use of the chromogenic vs one-stage factor activity assays in haemophilia A and B. Eur J Haematol. 2020;104(1):3-14. https://doi.org/10.1111/ejh.13339 PMid:31606899

9. Iorio A, Stonebraker JS, Chambost $H$, Makris M, Coffin D, Herr C, et al. Establishing the prevalence and prevalence at birth of hemophilia in males: A meta-analytic approach using national registries. Ann Intern Med. 2019;171(8):540-6. https:// doi.org/10.7326/m19-1208 PMid:31499529

10. Ratnoff OD, Davie EW. The Activation of Christmas factor (factor IX) by activated plasma thromboplastin antecedent (activated factor XI). Biochemistry. 1962;1(4):677-85. https:// doi.org/10.1021/bi00910a022

11. Ljung R, Auerswald G, Benson G, Dolan G, Duffy A, Hermans C, et al. Inhibitors in haemophilia A and B: Management of bleeds, inhibitor eradication and strategies for difficult-to-treat patients. Eur J Haematol. 2019;102(2):111-22. https://doi.org/10.1111/ ejh.13193

PMid:30411401

12. Nathwani AC. Gene therapy for hemophilia. Hematology Am 
Soc Hematol Educ Program. 2019;2019(1):1-8. PMid:31808868

13. O'Hara J, Walsh S, Camp C, Mazza G, Carroll L, Hoxer C, et al The impact of severe haemophilia and the presence of target joints on health-related quality-of-life. Health Qual Life Outcomes. 2018;16(1):84. https://doi.org/10.1186/s12955-018-0908-9 PMid:29720192

14. Karslieva MV. Endothelial-platelet Dysfunction in Young Patients with Connective Tissue Dysplasia. Author's Abstract of the Thesis for the Degree of Candidate of Medical Sciences. Stavropol; 2006. Available from: http://www.medical-diss.com/medicina/ endotelialno-trombotsitarnaya-disfunktsiya-u-molodyhpatsientov-s-displaziey-soedinitelnoy-tkani\#ixzz6gtfyGgTA. [Last accessed on 2021 Apr 28]

15. Martynov Al, Nechaeva GI, Akatova EV, Vershinina MV, Viktorova IA, Goltsova LG, et al. Clinical recommendations of the Russian scientific medical society of therapists for the diagnosis, treatment and rehabilitation of patients with connective tissue dysplasia. Med Bull North Caucasus. 2018;13(1-2):137-209. https://doi.org/10.14300/mnnc.2016.11001

16. Hickey SE, Varga EA, Kerlin B. Epidemiology of bleeding symptoms and hypermobile Ehlers-Danlos syndrome in paediatrics. Hemophilia. 2016;22(5):490-3. https://doi. org/10.1111/hae.13063

PMid:27562077

17. Sturov VG. Disorder of Blood Coagulation End-stage in Children and Adolescents with Systemic Mesenchymal Dysplasia Syndrome. Author's Abstract of Dissertation for the Degree of Doctor of Medical Sciences. Novosibirsk: 2008. Available from: http://www.medical-diss.com/medicina/ narusheniya-konechnogo-etapa-svertyvaniya-krovi-u-deteyi-podrostkov-s-sindromom-sistemnoy-mezenhimalnoydisplaziï\#ixzz5SbCCkGXy. [Last accessed on 2020 APr 29].

18. Kalayeva GY, Khokhlova OI. Undifferentiated connective tissue dysplasia in adolescents. Russ Bull Perinatol Pediatr. 2014;59(5):52-8. 